\section{Experimental investigation of factors controlling aragonite crystallization}

\section{MARIA CRISTINA CASTILLO ALVAREZ ${ }^{1}$, KIRSTY PENKMAN $^{2}$, ROLAND KROGER ${ }^{2}$, ADRIAN A FINCH ${ }^{1}$, MATTHIEU CLOG ${ }^{3}$ AND NICOLA ALLISON ${ }^{1}$}

\author{
${ }^{1}$ University of St. Andrews \\ ${ }^{2}$ University of York \\ ${ }^{3}$ SUERC
}

Presenting Author: mcca1@st-andrews.ac.uk

Ocean acidification reduces seawater $\mathrm{pH}$, shifts the dissolved inorganic carbon (DIC) equilibrium (increasing $\left[\mathrm{HCO}_{3}{ }^{-}\right]$and decreasing $\left[\mathrm{CO}_{3}{ }^{2-}\right]$ ) and reduces the calcification rates of many calcareous marine organisms. Aragonite and calcite precipitation rates are determined by the seawater saturation state, $\Omega$ (reflecting the availability of $\mathrm{CO}_{3}{ }^{2-}$ and $\mathrm{Ca}^{2+}$ for incorporation in the $\mathrm{CaCO}_{3}$ precipitate). However, both aqueous $\mathrm{HCO}_{3}{ }^{-}$and $\mathrm{CO}_{3}{ }^{2-}$ are inferred to attach to growing calcite crystal surfaces [1] and $\mathrm{HCO}_{3}{ }^{-}$is observed in both coral and synthetic aragonite [2]. Understanding the roles of both $\mathrm{HCO}_{3}^{-}$and $\mathrm{CO}_{3}{ }^{2-}$ in $\mathrm{CaCO}_{3}$ precipitation is key to predicting the responses of calcareous organisms to ocean acidification.

We are conducting experiments to study aragonite precipitation at a constant saturation state $(\Omega=4,7,10,13$ or 18$)$ over varying seawater $\mathrm{pH}$ levels $(\mathrm{pH}=8.337,8.545$ and 8.727). These changes in $\mathrm{pH}$ were accompanied by changes in [DIC]

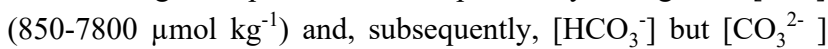
remains essentially unchanged. All experiments were conducted at $\mathrm{T}=25 \pm 0.1^{\circ} \mathrm{C}$, salinity $=34$ and using an aragonite seed. We correlated aragonite precipitation rates with concentrations of $\mathrm{CO}_{3}{ }^{2-}$ and $\mathrm{HCO}_{3}{ }^{-}$ions. Our results show that the precipitation rate of aragonite reflects the $\mathrm{CO}_{3}{ }^{2-}$ ion concentrations (fig 1) while $\mathrm{HCO}_{3}^{-}$ion concentrations has a negligible effect on precipitation rate (fig 2). This implies $\mathrm{HCO}_{3}^{-}$is not a substrate for aragonite formation and has important implications on the interpretation of $\mathrm{O}$ isotope proxies.

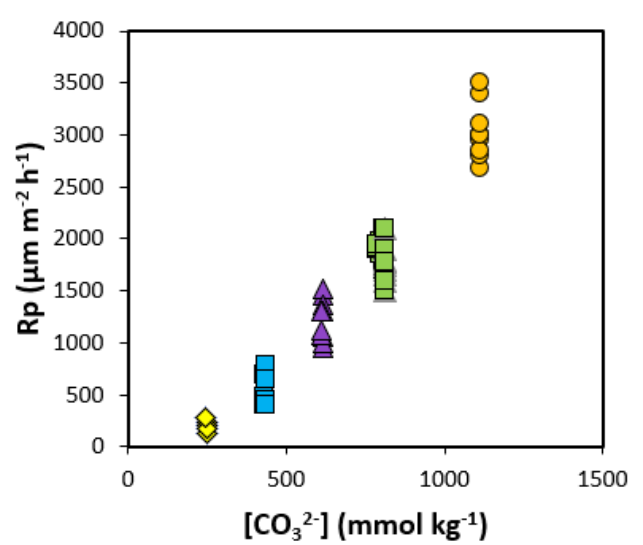

Figure 1 shows the precipitation rate of aragonite as a function of carbonate ion concentration. Different saturation states are denoted by different symbols: yellow diamonds show $\Omega=4$, blue squares $\Omega=7$, purple triangles $\Omega=10$, green squares $\Omega=13$ and orange circles $\Omega=18$

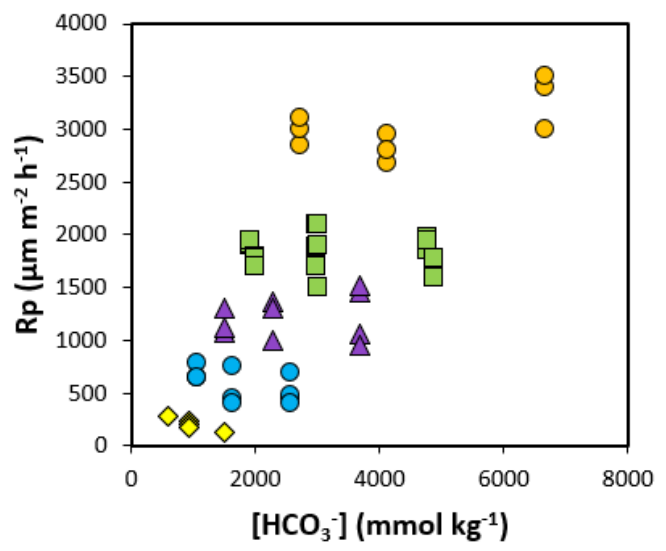

Figure 2 shows the precipitation rate of aragonite as a function of bicarbonate ion concentration. Different saturation states are denoted by different symbols: yellow diamonds show $\Omega=4$, blue squares $\Omega=7$, purple triangles $\Omega=10$, green squares $\Omega=13$ and orange circles $\Omega=18$ 